\title{
Phosphorylation of the Herpes Simplex Virus Type 1 Origin Binding Protein
}

\author{
JENNIFER A. ISLER AND PRISCILLA A. SCHAFFER* \\ Department of Microbiology and Cell and Molecular Biology Graduate Group, University of Pennsylvania School of \\ Medicine, Philadelphia, Pennsylvania 19104
}

Received 31 July 2000/Accepted 26 October 2000

\begin{abstract}
The herpes simplex virus type 1 (HSV-1) origin binding protein (OBP), the product of the UL9 gene, is one of seven HSV-encoded proteins required for viral DNA replication. OBP performs multiple functions characteristic of a DNA replication initiator protein, including origin-specific DNA binding and ATPase and helicase activities, as well as the ability to interact with viral and cellular proteins involved in DNA replication. Replication initiator proteins in other systems, including those of other DNA viruses, are known to be regulated by phosphorylation; however, the role of phosphorylation in OBP function has been difficult to assess due to the low level of OBP expression in HSV-infected cells. Using a metabolic labeling and immunoprecipitation approach, we obtained evidence that OBP is phosphorylated during HSV-1 infection. Kinetic analysis of metabolically labeled cells indicated that the levels of OBP expression and phosphorylation increased at approximately $4 \mathrm{~h}$ postinfection. Notably, when expressed from a transfected plasmid, a recombinant baculovirus, or a recombinant adenovirus (AdOBP), OBP was phosphorylated minimally, if at all. In contrast, superinfection of AdOBP-infected cells with an OBP-null mutant virus increased the level of OBP phosphorylation approximately threefold, suggesting that HSV-encoded viral or HSV-induced cellular factors enhance the level of OBP phosphorylation. Using HSV mutants inhibited at sequential stages of the viral life cycle, we demonstrated that this increase in OBP phosphorylation is dependent on early protein synthesis and is independent of viral DNA replication. Based on gel mobility shift assays, phosphorylation does not appear to affect the ability of OBP to bind to the HSV origins.
\end{abstract}

Most organisms replicate their genomes using a common mechanism in which DNA synthesis is initiated by a protein referred to as a replication initiator. Replication initiators are typically multifunctional proteins capable of (i) binding to the origin of DNA replication, (ii) unwinding origin DNA, and (iii) recruiting additional proteins necessary for DNA replication. Because initiator proteins control the onset of genome replication, their activities are often subject to strict regulation. Mounting evidence suggests that phosphorylation is a common regulatory mechanism among replication initiators (reviewed in reference 50). Perhaps the most extensively characterized replication initiator is the large tumor antigen (TAg) of simian virus 40 (SV40), whose ability to initiate viral DNA replication is both positively and negatively regulated by phosphorylation (reviewed in reference 40). Specifically, phosphorylation by cdc2 kinase stimulates the origin-binding activity of TAg, and dephosphorylation by protein phosphatase 2A (PP2A) facilitates cooperative hexamer assembly. Similarly, phosphorylation has been shown to affect the DNA replication activities of many other viral DNA replication initiator proteins, including polyomavirus TAg (49), the papillomavirus E1 protein (54), and the minute virus of mice (MVM) NS1 protein (12).

Herpes simplex virus type 1 (HSV-1) encodes seven proteins which are required for the replication of its DNA genome (37). These include a replication initiator or origin binding protein

* Corresponding author. Mailing address: Beth Israel Deaconess Medical Center, Harvard University, 330 Brookline Ave., RN125, Boston, MA 02215. Phone: (617) 667-2958. Fax: (617) 667-7175. E-mail: pschaffe@caregroup.harvard.edu.
(OBP; the product of the $U L 9$ gene), a heterotrimeric helicaseprimase complex (UL5,UL8, and UL52), a DNA polymerase (UL30), a polymerase accessory protein (UL42), and a singlestranded DNA binding protein referred to as ICP8 (UL29) (reviewed in reference 7). When expressed transiently in transfected Vero cells or in recombinant baculovirus-infected insect cells, these seven proteins can support the replication of a plasmid containing an HSV origin $(45,53)$. Whole-cell extracts containing these seven proteins have been shown to promote rolling-circle DNA replication using a primed plasmid as the template. In this model, however, plasmid amplification is independent of the presence of an HSV origin and of the replication initiator protein $\mathrm{OBP}(40,42)$. To date, attempts to reconstitute origin-dependent HSV DNA replication using the seven purified viral proteins have been unsuccessful, suggesting that cellular factors are also required.

Studies of other viral systems indicate that phosphorylation regulates the activities of replication initiator proteins at multiple levels, including origin binding activity (SV40 TAg, polyomavirus TAg, and bovine papillomavirus [BPV] E1) (32, 47, 51), oligomerization (SV40 TAg) (48), and DNA-unwinding activity (MVM NS1) (12). Thus, it is possible that phosphorylation regulates one or more of the multiple DNA replication functions of HSV OBP. In the current model of HSV DNA replication, OBP (i) binds to HSV origins, (ii) initiates ICP8stimulated unwinding of origin DNA, and (iii) recruits additional viral DNA replication proteins to the initiation site (reviewed in reference 7). OBP has been shown to dimerize and bind cooperatively to specific sequences (designated OBP binding sites I, II, and III) within the three HSV-1 origins of 
replication $(14,17)$, OriS (present in two copies), and OriL (present in one copy) $(20,44,49)$. DNA footprinting analysis and electron microscopy have demonstrated that cooperative binding of OBP to sites I and II in OriS loops and distorts the A+T-rich apex of the origin, which is thought to facilitate subsequent unwinding by the OBP-ICP8 protein complex (21, 25). By virtue of its six conserved helicase motifs, OBP is a member of the SF2 superfamily of helicases. In vitro, OBP exhibits ATP-dependent helicase activity which is unidirectional $\left(3^{\prime}\right.$ to $\left.5^{\prime}\right)$ and is stimulated by $\operatorname{ICP} 8(14,6)$. In cultured cells, five of the six conserved helicase motifs present within OBP have been shown to be essential for viral DNA replication (29). Finally, several reports indicate that OBP can interact with other members of the HSV-1 replication complex, including a member of the helicase-primase complex (UL8), the polymerase accessory protein (UL42), and the singlestranded DNA binding protein ICP8 $(29,33,5)$, and thus, OBP likely functions as a docking protein to recruit these essential replication proteins to the viral origins.

A unique transcript which originates within the OBP open reading frame (ORF) encodes a truncated form of OBP, designated OBPC (UL8.5) (3). OBPC is comprised of the Cterminal 480 amino acids of OBP, which include the DNA binding domain (3). Whereas OBP is an early protein, OBPC is expressed with late (L) kinetics (3). Although the precise role of OBPC in the HSV life cycle has not been established, overexpression of either OBPC or truncated C-terminal peptides of OBP has been shown to inhibit viral DNA replication in HSV-infected cells, presumably by occupying binding sites I, II, and III in viral origins and failing to promote initiation (4, 38, 45). Moreover, studies conducted with OBP-expressing cells have shown that the copy number of resident OBP-expressing genes is a critical determinant of HSV replication efficiency (27). These observations suggest that the level and/or activity of OBP is critical for efficient HSV DNA replication, and thus, OBP is likely subject to strict regulation during the viral life cycle (27).

Regulation of the functions of other viral replication initiator proteins by phosphorylation has been well established (50); however, assessment of the phosphorylation state of OBP has been challenging due to the very low level of OBP expressed in HSV-infected cells (37). Here, we demonstrate that OBP is indeed phosphorylated during HSV infection and that HSVencoded viral or HSV-induced cellular factors enhance the level of OBP phosphorylation. Furthermore, we demonstrate that HSV-induced phosphorylation of OBP is dependent on early (E) protein synthesis and independent of viral DNA replication. Gel mobility shift assays suggest that phosphorylation does not affect the origin binding activity of OBP; however, OBP and/or other proteins within an OBP-containing complex are likely phosphorylated when bound to its cognate binding site, site I. Based on the results presented here, OBP differs from other viral replication initiator proteins in that it is synthesized and phosphorylated at very low levels in HSVinfected cells, and its phosphorylation appears to be dependent, at least in part, on viral infection. That these unique properties of OBP may reflect characteristics of the replication initiation complex specific to HSV and play a role in the pathogenesis of the virus is of considerable interest.

\section{MATERIALS AND METHODS}

Cells, viruses, and plasmids. Vero cells (ATCC CCL-81) were propagated and maintained as described previously (10). PC12 cells (a gift of John Wagner, Cornell University, Medical College, New York, N.Y.) were grown and differentiated for 7 days with nerve growth factor (NGF) as described previously (16). HSV-1 wild-type strain KOS was used throughout these studies. The KOSderived OBP null mutant virus $h r 94$ and the OBP-expressing Vero cell line 2B.11 were generously provided by Sandy Weller (University of Connecticut, Farmington) (27). $h r 94$ contains a lac $Z$ insertion in the ORF of the $U L 9$ gene such that it does not express OBP, and the $2 \mathrm{~B} .11$ cell line contains the $U L 9$ gene under the control of the ICP 6 promoter. The KOS-derived ICP 4 mutant $n 12$ has been described elsewhere (11). HSV infections were performed using $3.5 \times 10^{6}$ Vero cells per 100-mm-diameter plate at a multiplicity of infection (MOI) of 10 $\mathrm{PFU} /$ cell at $37^{\circ} \mathrm{C}$. High MOIs were used to enhance OBP levels and thus facilitate the detection of OBP synthesis and phosphorylation by metabolic labeling. UV inactivation of wild-type KOS was achieved by exposing 35-mm-diameter dishes containing 1.5-ml aliquots of virus suspension in complete Dulbecco modified Eagle medium to UV radiation $\left(1 \mathrm{~J} / \mathrm{cm}^{2}\right)$ in a Stratalinker (Stratagene, La Jolla, Calif.) for $5 \mathrm{~min}$. This treatment reduced the viral titer from $5 \times 10^{9}$ $\mathrm{PFU} / \mathrm{ml}$ to less than $4 \mathrm{PFU} / \mathrm{ml}$.

In transient-expression assays, $4.5 \times 10^{6} 293 \mathrm{~T}$ cells (provided by Paul Bates, University of Pennsylvania, Philadelphia) per 100-mm-diameter collagen-coated plate were transfected with $10 \mu \mathrm{g}$ of plasmid by the Lipofectin method (Gibco, Grand Island, N.Y.). The plasmids used in this study included OBP-expressing plasmid pCMVUL9 (18), ICP0-expressing plasmid pSH (8), and green fluorescent protein (GFP)-expressing plasmid EGFP-N1 (Clontech, San Francisco, Calif.).

The baculovirus (Autographa californica polyhedrosis virus [AcNPV]) which expresses UL9 (AcNPVUL9) was generously provided by Debbie Parris (Ohio State University, Columbus) with permission from Bob Lehman (Stanford University, Palo Alto, Calif.) (13). The SV40 large TAg-expressing baculovirus AcNPVTAg was generously provided by Ellen Fanning (Vanderbilt University, Nashville, Tenn.) (19) and was used as a positive control for protein phosphorylation in baculovirus-infected cells. Wild-type baculovirus (Invitrogen, Carlsbad, Calif.) was used as a negative control. All baculovirus infections were performed at $28^{\circ} \mathrm{C}$ in Grace's complete medium (Invitrogen) using $10^{6}$ Spodoptera frugiperda (Sf9) cells (Invitrogen) per 60-mm-diameter plate at an MOI of $10 \mathrm{PFU} /$ cell.

The OBP-expressing adenovirus (AdOBP) contains the entire OBP ORF under the control of a tetracycline-inducible promoter. For AdOBP infections, $3.5 \times 10^{6}$ Vero cells per 100 -mm-diameter plate were coinfected with AdOBP $(\mathrm{MOI}=50)$ and AdTta $(\mathrm{MOI}=10)$ in the presence of $1 \mu \mathrm{M}$ doxycycline at $37^{\circ} \mathrm{C}$. AdTta expresses the tetracycline transactivator and thus activates expression of OBP in the presence of doxycycline. Similar infections were performed using a GFP-expressing adenovirus (AdGFP) and an ICP0-expressing adenovirus (AdICP0). Recombinant adenoviruses were constructed in collaboration with Bill Halford (Tulane University, New Orleans, La.). In some cases, AdOBPinfected cells were subsequently superinfected with HSV mutants. Superinfections were performed $24 \mathrm{~h}$ after infection at an MOI of $50 \mathrm{PFU} / \mathrm{cell}$.

Metabolic labeling and immunoprecipitation of OBP. Throughout this study, $\left[{ }^{35} \mathrm{~S}\right]$ methionine and $\left[{ }^{32} \mathrm{P}\right]$ orthophosphate (Dupont/NEN, Boston, Mass.) were used to metabolically label infected cells. Thirty minutes prior to labeling, cells were washed with Dulbecco modified Eagle medium containing $2.5 \%$ fetal bovine serum lacking either methionine or sodium phosphate (Gibco), respectively, and incubated in this medium for $30 \mathrm{~min}$ at $37^{\circ} \mathrm{C}$. At the time of labeling, methionine-free medium containing $\left[{ }^{35} \mathrm{~S}\right]$ methionine at $40 \mu \mathrm{Ci} / \mathrm{ml}$ or phosphatefree medium containing $\left[{ }^{32} \mathrm{P}\right]$ orthophosphate at $0.3 \mathrm{mCi} / \mathrm{ml}$ was added to the cells. Labeling times are indicated for individual experiments. At the time of harvest, radioactive medium was removed and cells were washed twice with cold phosphate-buffered saline (PBS) and then scraped into PBS. Cells were pelleted by centrifugation, the PBS was removed, and the cell pellets were freeze-thawed once. Lysed cell pellets were resuspended in radioimmunoprecipitation assay buffer (150 mM NaCl, $50 \mathrm{mM}$ Tris [pH 7.5], 0.1\% sodium dodecyl sulfate [SDS], $1 \%$ NP-40, $0.5 \%$ deoxycholate) supplemented with inhibitors of phosphatases and proteases $(10 \mathrm{mM}$ sodium fluoride, $10 \mu \mathrm{M}$ sodium orthovanadate, aprotinin at $1 \mu \mathrm{g} / \mathrm{ml}$, pepstatin at $1 \mu \mathrm{g} / \mathrm{ml}$, leupeptin at $1 \mu \mathrm{g} / \mathrm{ml}$ ), and the resulting suspension was vortexed and centrifuged at $14,000 \times \mathrm{g}$ for $20 \mathrm{~min}$ at $4^{\circ} \mathrm{C}$ to pellet protein aggregates. The supernatant was then precleared with protein A-agarose (Gibco). For immunoprecipitation assays, the resulting lysates were incubated with the indicated antibody at $4^{\circ} \mathrm{C}$ overnight with gentle rocking. Protein A agarose was added, and incubation was continued for an additional hour. Immunoprecipitates were pelleted by centrifugation at $3,000 \times g$ at $4^{\circ} \mathrm{C}$ for $5 \mathrm{~min}$. Pellets were washed three times with radioimmunoprecipitation assay buffer 
prior to resuspension in a denaturing protein sample buffer (50 mM Tris, 100 mM dithiothreitol, $2 \%$ SDS, $10 \%$ glycerol, $0.1 \%$ bromophenol blue). Proteins were analyzed by electrophoresis in a discontinuous $7.5 \%$ polyacrylamide (19:1, acrylamide-bisacrylamide ratio) gel.

Antibodies used for immunoprecipitation include anti-OBP (RH7, rabbit polyclonal) antibody (provided by Debbie Parris with permission from Daniel Tenney, Bristol-Meyers Squibb, Wallingford, Conn.) (34), anti-glycoprotein D (antigD; R45, rabbit polyclonal) antibody (provided by Richard Courtney, Pennsylvania State University Health Sciences Center, Hershey), anti-ICP0 (H112, mouse monoclonal) antibody (1), and anti-TAg (Ab-1, mouse monoclonal; Oncogene Research Products, Cambridge, Mass.) antibody.

Viral DNA replication assay. Vero cells infected as described above were harvested at $10 \mathrm{~h}$ postinfection (hpi), and total DNA was harvested using the QIAGEN blood and tissue kit (QIAGEN, Valencia, Calif.). Three micrograms of DNA was vacuum slot blotted onto a nylon membrane (GeneScreen; New England Nuclear Research Products, Boston, Mass.) as described previously (43). After UV cross-linking, the membrane was prehybridized for $1 \mathrm{~h}$ at $55^{\circ} \mathrm{C}$ in ExpressHyb solution (Clontech) and hybridized with a radiolabeled probe $(3 \times$ $10^{6} \mathrm{cpm} / \mathrm{ml}$ ) specific for the HSV-1 UL26 gene (encoding capsid protein VP24) for $3 \mathrm{~h}$ at $55^{\circ} \mathrm{C}$. The membrane was then washed in accordance with the ExpressHyb protocol (Clontech) and exposed in a PhosphorImager cassette (Molecular Dynamics, Sunnyvale, Calif.) for $4 \mathrm{~h}$.

Gel mobility shift assay and phosphatase treatment. Nuclear extracts of HSVinfected Vero or NGF-differentiated PC12 cells were prepared as previously described (16). Total protein concentrations were measured by the method of Bradford (Bio-Rad, Hercules, Calif.) using a standard curve generated with bovine serum albumin as the protein source. Gel shift reactions were performed in a total volume of $10 \mu \mathrm{l}$ containing $5 \mu \mathrm{g}$ of nuclear protein, $1 \times$ binding buffer (10\% glycerol, $50 \mathrm{mM}$ HEPES [pH 7.9], $0.1 \mathrm{mM}$ EDTA, $100 \mathrm{mM} \mathrm{NaCl}$ with protease inhibitors), $1.5 \mu \mathrm{g}$ of poly(dA-dT), and $1 \mathrm{ng}$ of double-stranded DNA probe $\left(8 \times 10^{5} \mathrm{cpm} / \mathrm{ml}\right)$. The 24 -bp probe used contains the high-affinity binding site for OBP, site I, that is present in OriS and consists of the sequence 5'AA GCGTTCGCACTTCGTCCCAATA3'. Binding reaction mixtures were incubated at room temperature for $30 \mathrm{~min}$, and protein-DNA complexes were resolved by electrophoresis in a $6 \%$ nondenaturing polyacrylamide (19:1, acrylamide-bisacrylamide ratio) gel at $4^{\circ} \mathrm{C}$. In binding reaction mixtures involving antibody, anti-OBP (R250) antibody (provided by Mark Challberg, National Institute of Allergy and Infectious Diseases, Bethesda, Md.) was added after 5 min and incubation was allowed to continue for the remaining $25 \mathrm{~min}$.

In experiments involving phosphatase treatment, gel shift reactions were prepared in the absence of probe and increasing amounts of either $\lambda$ phosphatase or PP1 (New England Biolabs, Beverly, Mass.) were added. In control samples, PP1 storage buffer (New England Biolabs) was added. Reaction mixtures were supplemented with $\mathrm{MnCl}_{2}$ at a concentration of $1 \mathrm{mM}$ ( $\lambda$ phosphatase) or $2 \mathrm{mM}$ (PP1), incubated for $1 \mathrm{~h}$ at $30^{\circ} \mathrm{C}$, and then chilled on ice. After $5 \mathrm{~min}$, probe was added and reaction mixtures were incubated at room temperature for an additional $30 \mathrm{~min}$. Protein-DNA complexes were then analyzed by nondenaturing acrylamide gel electrophoresis as described above.

\section{RESULTS}

Detection of OBP in HSV-infected cells. In light of the low level of OBP present in HSV-infected cells (37), we first sought to determine whether OBP could be detected in $\left[{ }^{35} \mathrm{~S}\right]$ methionine-labeled cells infected with HSV. Vero cells were infected with either KOS or hr94 (an OBP null mutant) and labeled with $\left[{ }^{35} \mathrm{~S}\right]$ methionine from 6 to 8 hpi. Additionally, 2B.11 cells, Vero cells which contain the $U L 9$ gene under the control of the ICP6 promoter, were either mock infected or infected with hr94 and labeled as described above. At 8 hpi, cells were harvested and total protein was subjected to immunoprecipitation (Fig. 1A) with a polyclonal antibody specific for OBP (RH7) or with a control antibody directed against HSV gD (R45). The predicted molecular mass of OBP is $\sim 95 \mathrm{kDa}(36)$. Antibody to OBP precipitated a protein of $\sim 100 \mathrm{kDa}$ from KOS-infected but not from $h r 94$-infected Vero cells (lanes 1 and 2). As anticipated, this antibody also precipitated a protein with identical mobility from $h r 94$-infected but not mock-infected 2B.11 cells (lanes 4 and 3). The intense band which
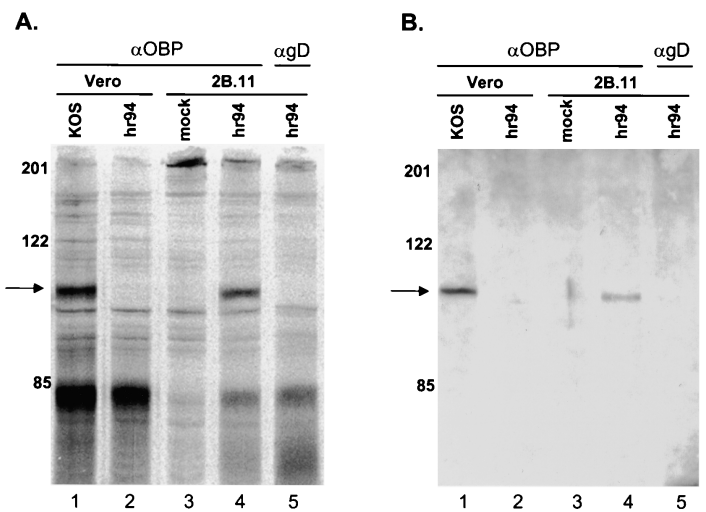

FIG. 1. Detection of OBP in HSV-infected cells. (A) Vero cells (lanes 1 and 2) or 2B.11 cells (lanes 3, 4, and 5) were mock infected (lane 3) or infected at $10 \mathrm{PFU} /$ cell with KOS (lane 1) or hr94 (lane 2, 4 , and 5) and labeled with ${ }^{35}$ S $]$ methionine from 6 to 8 hpi. Cells were harvested at $8 \mathrm{hpi}$, and lysates were subjected to immunoprecipitation with a polyclonal rabbit antibody to OBP $(\alpha \mathrm{OBP})(\mathrm{RH} 7)$ or a polyclonal rabbit antibody to $\mathrm{gD}(\alpha \mathrm{gD})(\mathrm{R} 45)$. Immunoprecipitates were resolved by SDS-PAGE and visualized using a PhosphorImager. (B) Infections were carried out as described for panel A except that no $\left[{ }^{35} \mathrm{~S}\right]$ methionine was added. Immunoprecipitates were resolved by SDS-PAGE, followed by Western blot analysis using an alternative antibody to OBP (R250). The locations of molecular weight markers (in kilodaltons) are indicated on the left of each panel, and the arrows indicate the locations of OBP-specific bands.

migrated at $\sim 85 \mathrm{kDa}$ (lanes $1,2,4$, and 5) is a virus-specific protein which precipitates nonspecifically (data not shown). The antibody specific for $\mathrm{gD}$ did not precipitate an $\sim 100-\mathrm{kDa}$ protein from $h r 94-i n f e c t e d 2$ B.11 cells (lane 5).

To verify that the $\sim 100-\mathrm{kDa}$ protein was OBP, we performed Western blot analysis on immunoprecipitated samples (Fig. 1B). The infections and immunoprecipitations described above were repeated using unlabeled infected-cell extracts, and immunoprecipitated proteins were analyzed by Western blot assay using a second antibody to OBP (R250). The $~ 100-$ $\mathrm{kDa}$ protein was specifically recognized by this antibody (lanes 1 and 4), indicating that this protein is indeed OBP.

Phosphorylation of OBP in $\mathbf{H S V}$-infected cells. To determine whether OBP, like other viral replication initiator proteins, is phosphorylated, Vero cells were infected with KOS and metabolically labeled with $\left[{ }^{32} \mathrm{P}\right]$ orthophosphate from 6 to 8 hpi. In parallel, HSV-infected cells were labeled with $\left[{ }^{35} \mathrm{~S}\right]$ methionine to analyze the levels of OBP synthesis. At 8 hpi, total protein was harvested and OBP was immunoprecipitated. A $\left[{ }^{32} \mathrm{P}\right]$ orthophosphate-labeled protein of $\sim 100 \mathrm{kDa}$ with mobility corresponding to that of $\left[{ }^{35} \mathrm{~S}\right]$ methionine-labeled OBP was detected in KOS-infected but not in $h r 94$-infected cells, indicating that OBP is phosphorylated in HSV-infected cells (Fig. 2). The $\left[{ }^{32} \mathrm{P}\right]$ orthophosphate-labeled bands that range in size from 70 to $95 \mathrm{kDa}$ and the bands at 122 and 200 $\mathrm{kDa}$ precipitate nonspecifically using antibody specific for OBP (RH7) together with protein A-agarose; these bands can also be seen in the $\left[{ }^{35} \mathrm{~S}\right]$ methionine-labeled gel. Since OBPC is not precipitated with this antibody to OBP ( $\mathrm{RH} 7)$, the phosphorylation state of OBPC has not yet been determined.

Kinetics of OBP synthesis and phosphorylation. To determine the time at which OBP is phosphorylated during HSV 

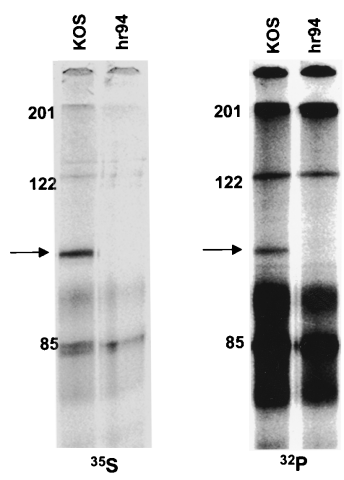

FIG. 2. Phosphorylation of OBP in HSV-infected cells. Vero cells were infected at $10 \mathrm{PFU} / \mathrm{cell}$ with KOS or $h r 94$ and labeled with either $\left[{ }^{35} \mathrm{~S}\right]$ methionine or $\left[{ }^{32} \mathrm{P}\right]$ orthophosphate from 6 to 8 hpi. Cells were harvested at $8 \mathrm{hpi}$, and lysates were subjected to immunoprecipitation with antibody to OBP (RH7). Immunoprecipitates were resolved by SDS-PAGE and visualized using a PhosphorImager. The locations of molecular weight markers (in kilodaltons) are shown to the left of the KOS lanes; the arrows indicate the locations of OBP. (The $\left[{ }^{32} \mathrm{P}\right]$ orthophosphate-labeled proteins which migrate from $\sim 70$ to 95 $\mathrm{kDa}$ precipitate nonspecifically upon addition of $\mathrm{RH} 7$ [anti-OBP] and protein A-agarose [data not shown]; these proteins were also detected in $\left[{ }^{35}\right.$ S $]$ methionine-labeled extracts, albeit at lesser intensities.)

infection, we performed a time course experiment in which Vero cells were infected with KOS in the presence of $\left[{ }^{35} \mathrm{~S}\right] \mathrm{me}-$ thionine ( 0 hpi) and harvested at 4, 8, 12, and 16 hpi (Fig. 3A). $\left[{ }^{35} \mathrm{~S}\right]$ methionine-labeled OBP was detected by $4 \mathrm{hpi}$ and reached maximum levels by $12 \mathrm{hpi}$. As seen in the enlargement to the right of the $\sim 100-\mathrm{kDa}$ bands in Fig. 3A, a slight increase in the electrophoretic mobility of OBP was evident between 4 and $8 \mathrm{hpi}$. Despite an increase in the level of $\left[{ }^{35} \mathrm{~S}\right] \mathrm{methionine-}$ labeled OBP, no further shift in electrophoretic mobility was observed after 8 hpi. To determine whether this shift in mobility is associated with the phosphorylation state of OBP, we performed $\left[{ }^{35} \mathrm{~S}\right]$ methionine and $\left[{ }^{32} \mathrm{P}\right]$ orthophosphate labeling of OBP in parallel at various times postinfection (Fig. 3B). Vero cells were infected with KOS and pulse-labeled with either $\left[{ }^{35} \mathrm{~S}\right]$ methionine or $\left[{ }^{32} \mathrm{P}\right]$ orthophosphate from 2 to 4,4 to 6 , and 6 to 8 hpi. Cells were harvested immediately following each 2-h labeling period, and lysates were subjected to immunoprecipitation with antibody to OBP (RH7). The levels of $\left.{ }^{[35} \mathrm{S}\right]$ methionine-labeled OBP were higher in cells labeled from 4 to 6 and 6 to $8 \mathrm{hpi}$, relative to 2 to $4 \mathrm{hpi}$, consistent with the kinetics of expression of OBP as an E protein. A shift in the electrophoretic mobility of $\left[{ }^{35} \mathrm{~S}\right]$ methionine-labeled OBP is not obvious in Fig. 3B relative to Fig. 3A, presumably due to the shorter labeling period and/or a reduction in the duration of gel electrophoresis, resulting in reduced protein separation. The levels of $\left[{ }^{32} \mathrm{P}\right]$ orthophosphate-labeled OBP were also higher in cells labeled from 4 to 6 and 6 to 8 hpi than 2 to $4 \mathrm{hpi}$, in which the band was barely detectable. Thus, it appears that the level of phosphorylated OBP increases simultaneously with the increase in OBP synthesis observed at this time. Notably, the time at which we detect an increase in the level of $\left[{ }^{32} \mathrm{P}\right]$ orthophosphate-labeled OBP ( $\sim 4 \mathrm{hpi}$ and later $)$ is consistent with the time at which we observed a shift in the electrophoretic mobility of OBP (between 4 and 8 hpi; Fig. 3A), suggesting that this shift was a result of phosphorylation.
HSV infection-specific factors enhance OBP phosphorylation. Because phosphorylation of initiator proteins of other DNA-containing viruses is independent of virus replication, we next sought to examine the effect of HSV replication on the phosphorylation state of OBP. To this end, we performed $\left[{ }^{32} \mathrm{P}\right]$ orthophosphate labeling and immunoprecipitation of OBP expressed by three independent methods: (i) 293T cells transfected with OBP expression plasmid pCMVUL9, (ii) Sf9 cells infected with OBP-expressing baculovirus AcNPVUL9, and (iii) Vero cells infected with OBP-expressing adenovirus AdOBP (Fig. 4).

Highly transfectable 293T cells were transfected with EGFP-N1 (expressing GFP; this plasmid was used to measure the efficiency of transfection), pCMVUL9 (expressing OBP), or pSH (expressing ICP0); labeled with $\left[{ }^{35} \mathrm{~S}\right]$ methionine or $\left[{ }^{32} \mathrm{P}\right]$ orthophosphate from 12 to $24 \mathrm{~h}$ posttransfection (hpt); and subjected to immunoprecipitation analysis (Fig. 4A). ICP0 was used as a control for phosphorylation by cellular kinases, since it is known to be highly phosphorylated in the absence of other HSV proteins (1). Synthesis of both OBP and ICP0 was detected, ICP0 being synthesized at higher levels than OBP $\left(\left[{ }^{35} \mathrm{~S}\right]\right.$ methionine-labeled bands in Fig. 4A). Whereas ICP0 was very efficiently phosphorylated, we were unable to detect

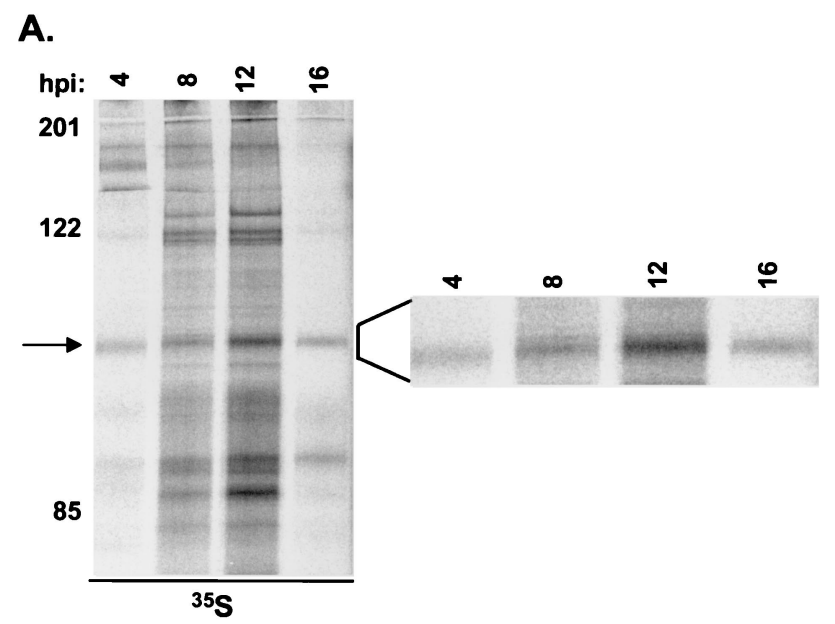

B.

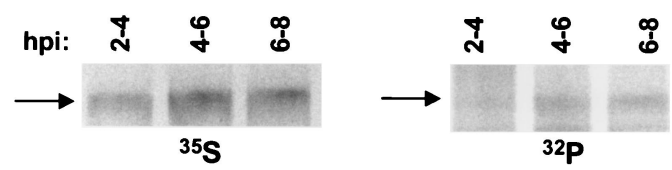

FIG. 3. Kinetics of OBP synthesis and phosphorylation. (A) Vero cells were infected at $10 \mathrm{PFU} / \mathrm{cell}$ with KOS in the presence of $\left[{ }^{35} \mathrm{~S}\right] \mathrm{me}-$ thionine and harvested at 4, 8, 12, and 16 hpi. Lysates were subjected to immunoprecipitation with antibody to OBP (RH7), and immunoprecipitates were resolved by SDS-PAGE and visualized using a PhosphorImager. The locations of molecular weight markers (in kilodaltons) are shown at the left, and the arrow indicates the location of OBP. The bands to the right are magnified versions of those on the left. (B) Vero cells were infected at $10 \mathrm{PFU} /$ cell with KOS and labeled with either $\left[{ }^{35} \mathrm{~S}\right]$ methionine or $\left[{ }^{32} \mathrm{P}\right]$ orthophosphate from 2 to 4,4 to 6 , and 6 to 8 hpi. Cells were harvested at 4, 6, and $8 \mathrm{hpi}$, respectively. Lysates were subjected to immunoprecipitation with antibody to OBP (RH7), and immunoprecipitates were resolved by SDS-PAGE and visualized using a PhosphorImager. 

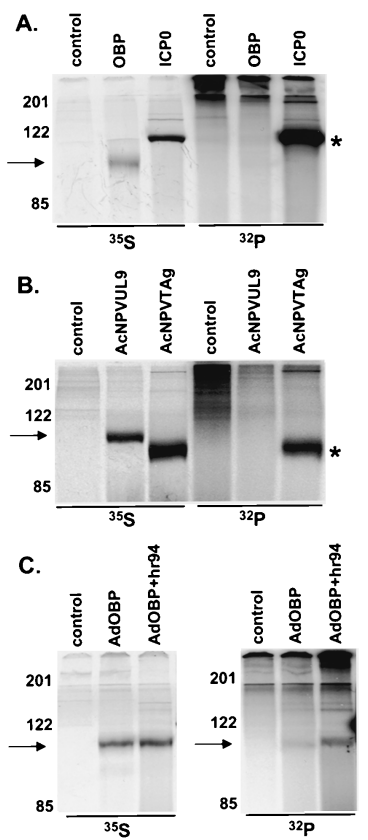

FIG. 4. OBP synthesis and phosphorylation in 293T, Sf9, and Vero cells. (A) $293 \mathrm{~T}$ cells were transfected with a GFP-expressing plasmid (control) or with pCMVUL9 (OBP) or pSH (ICP0). Cells were labeled with either $\left[{ }^{35} \mathrm{~S}\right]$ methionine or $\left[{ }^{32} \mathrm{P}\right]$ orthophosphate from 16 to $24 \mathrm{hpt}$. At $24 \mathrm{hpt}$, cells were harvested and total protein extracts were subjected to immunoprecipitation as follows: antibody to OBP (RH7) was added to control- and OBP-transfected cell lysates, and antibody to ICP0 (H112) was added to ICP0-transfected cell lysates. Immunoprecipitated proteins were resolved by SDS-PAGE and visualized using a PhosphorImager. The locations of molecular weight markers (in kilodaltons) are shown on the left, as is an arrow indicating the location of OBP. An asterisk indicates the location of ICP0. (B) Sf9 cells were infected at an MOI of $50 \mathrm{PFU} /$ cell with wild-type AcNPV (control), AcNPVUL9, or AcNPVTAg and labeled with either $\left[{ }^{35} \mathrm{~S}\right]$ methionine or $\left[{ }^{32} \mathrm{P}\right]$ orthophosphate from 30 to $38 \mathrm{hpi}$. At $38 \mathrm{hpi}$, cells were harvested and total protein extracts were subjected to immunoprecipitation as follows: antibody to OBP (RH7) was added to wild-type ACNPVand AcNPVUL9-infected samples, and antibody to TAg was added to AcNPVTAg-infected cells. Immunoprecipitated proteins were analyzed, and molecular weight markers are as described for panel A. An asterisk indicates the location of TAg. (C) Vero cells were infected at $50 \mathrm{PFU} /$ cell with a recombinant adenovirus expressing GFP (control) or OBP (AdOBP). At $24 \mathrm{hpi}$, a subset of AdOBP-infected cells were superinfected at $50 \mathrm{PFU} /$ cell with an OBP-null mutant, $h r 94$ (AdOBP + hr94). Cells were labeled with either $\left.{ }^{35} \mathrm{~S}\right]$ methionine or $\left[{ }^{32} \mathrm{P}\right.$ ] orthophosphate from 4 to $8 \mathrm{~h}$ following $h r 94$ superinfection (28 to $32 \mathrm{~h}$ following AdOBP infection). At $8 \mathrm{hpi}$, cells were harvested and total protein extracts were subjected to immunoprecipitation with antibody to OBP (RH7). Proteins were analyzed, and molecular weight markers are as described for panel A.

$\left[{ }^{32} \mathrm{P}\right]$ orthophosphate-labeled OBP, suggesting that OBP is not phosphorylated in transfected $293 \mathrm{~T}$ cells. We were also unable to detect phosphorylation of OBP in Vero cells transfected with pCMVUL9, although the levels of protein synthesis were much lower than that observed in $293 \mathrm{~T}$ cells (data not shown).

In the second test, Sf9 cells were infected with wild-type baculovirus (AcNPV; control) or a recombinant baculovirus expressing either OBP (AcNPVUL9) or SV40 TAg (AcNPVTAg) (Fig. 4B). TAg was used as a positive control for phosphorylation in this test, since it has been shown to be efficiently phosphorylated in Sf9 cells when synthesized in the absence of other SV40 proteins (19). As detected by $\left[{ }^{35}\right.$ S $]$ methionine labeling and immunoprecipitation, both OBP and TAg were synthesized efficiently in baculovirus-infected cells; however, although TAg was highly phosphorylated, we were unable to detect $\left[{ }^{32} \mathrm{P}\right]$ orthophosphate-labeled OBP. These results demonstrate that OBP is not phosphorylated when expressed from a recombinant baculovirus in Sf9 cells and are consistent with our inability to detect phosphorylation of OBP in pCMVUL9transfected 293T cells.

In the third test, Vero cells were infected with a recombinant adenovirus expressing GFP (AdGFP; negative control) or OBP (AdOBP). We also sought to determine whether HSV infection could stimulate phosphorylation of OBP in these tests (Fig. 4C). Therefore, at $24 \mathrm{hpi}$, a subset of AdOBPinfected cells was mock infected or superinfected with OBPnull mutant virus $h r 94$. Infected cells were labeled with either $\left[{ }^{35} \mathrm{~S}\right]$ methionine or $\left[{ }^{32} \mathrm{P}\right]$ orthophosphate from 28 to $32 \mathrm{~h}$ following adenovirus infection (this corresponds to 4 to $8 \mathrm{~h}$ following superinfection with $h r 94)$, and cell lysates were subjected to immunoprecipitation with antibody to OBP (RH7). The results of $\left.{ }^{35} \mathrm{~S}\right]$ methionine-labeling experiments demonstrated that the level of OBP synthesis was nearly equivalent in AdOBP-infected cells, regardless of $h r 94$ superinfection. In contrast, whereas a very low level of $\left[{ }^{32} \mathrm{P}\right]$ orthophosphate-labeled OBP was detected in cells infected with AdOBP alone, superinfection with $h r 94$ increased the level of $\left[{ }^{32} \mathrm{P}\right]$ orthophosphate-labeled OBP threefold. These results suggest that an HSV-encoded or HSV-induced factor(s) enhances the level of OBP phosphorylation.

HSV-specific phosphorylation of OBP is dependent on $E$ protein synthesis. We next sought to determine whether a specific class of viral genes is responsible for the increased level of OBP phosphorylation observed upon superinfection of AdOBP-infected cells with $h r 94$ (Fig. 4C). For this purpose, Vero cells were infected with AdOBP and superinfected with a panel of HSV mutants blocked at various stages of the HSV replication cycle (Fig. 5). As illustrated in Fig. 5A, superinfection of AdOBP-infected cells with UV-inactivated KOS, $n 12$ (an ICP4-null mutant), or $h r 94$ in the presence or absence of phosphonoacetic acid (PAA) inhibits HSV infection at sequential stages of the viral replication cycle. Cells were labeled with $\left[{ }^{35} \mathrm{~S}\right]$ methionine or $\left[{ }^{32} \mathrm{P}\right]$ orthophosphate from 4 to $8 \mathrm{~h}$ following superinfection (Fig. 5B). Superinfection of AdOBP-infected cells with UV-inactivated KOS or $n 12$ (lanes 2 and 3) produced levels of $\left[{ }^{35} \mathrm{~S}\right]$ methionine-labeled OBP which were noticeably higher than that observed in cells infected with AdOBP alone (lane 1) or in cells superinfected with $h r 94$, in either the presence or the absence of PAA (lanes 4 and 5). The level of $\left[{ }^{32} \mathrm{P}\right]$ orthophosphate-labeled OBP in cells infected with AdOBP alone was barely detectable (lane 6), consistent with the level shown in Fig. 4C. Similarly, very low levels of $\left[{ }^{32} \mathrm{P}\right]$ orthophosphate-labeled OBP were detected in AdOBPinfected cells superinfected with UV-inactivated KOS (lane 7) or $n 12$ (lane 8 ). In contrast, the level of $\left[{ }^{32} \mathrm{P}\right]$ orthophosphatelabeled OBP detected in AdOBP-infected cells superinfected with $h r 94$, in either the presence (lane 9) or the absence (lane 10) of PAA, was appreciably higher. That the level of OBP phosphorylation was greater in $h r 94$-superinfected cells (with or without PAA) is further emphasized by the level of OBP synthesis in these cells. As noted above, although less $\left[{ }^{35} \mathrm{~S}\right] \mathrm{me}-$ 
A.

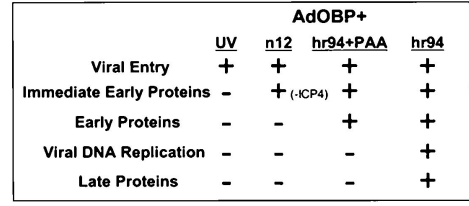

B.

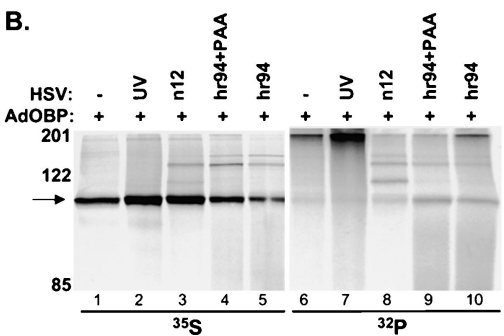

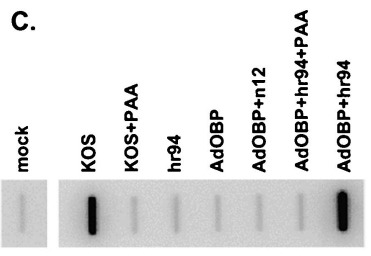

D.

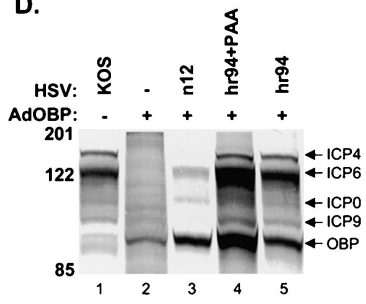

FIG. 5. Phosphorylation of OBP is dependent on E protein synthesis. (A) Chart indicating patterns of HSV gene expression in AdOBP-infected Vero cells superinfected with the HSV mutants indicated. (B) Vero cells were infected at $50 \mathrm{PFU} /$ cell with AdOBP. Twenty-four hours later, cells were mock superinfected $(-)$ or superinfected $(+)$ at an MOI of $50 \mathrm{PFU} /$ cell with either UV-inactivated wild-type KOS (UV), an ICP4-null mutant ( $n 12), h r 94$ in the presence of PAA at $400 \mu \mathrm{g} / \mathrm{ml}$ (hr94+PAA), or $h r 94$ without PAA (hr94). Cells were labeled with either $\left[{ }^{35} \mathrm{~S}\right]$ methionine or $\left[{ }^{32} \mathrm{P}\right]$ orthophosphate from 4 to $8 \mathrm{~h}$ following superinfection. All samples were immunoprecipitated with antibody to OBP (RH7) and analyzed as described in the legend to Fig. 4A. (C) Vero cells were infected at 50 PFU/ cell with the viruses indicated in the presence or absence of PAA at $400 \mu \mathrm{g} / \mathrm{ml}$ (as noted). Total DNA was extracted at 10 hpi; $3 \mu \mathrm{g}$ of DNA was blotted onto a nitrocellulose membrane, UV cross-linked, and hybridized to a labeled UL26 probe; and the membrane was exposed in a PhosphorImager. (D) Synthesis of HSV proteins in AdOBP-infected cells superinfected with the viruses indicated and labeled with $\left[{ }^{35} \mathrm{~S}\right]$ methionine from 3 to $10 \mathrm{~h}$ following superinfection. Proteins from total cell lysates were resolved in a discontinuous $9 \%$ polyacrylamide gel and visualized using a PhosphorImager. Arrows indicate the locations of IE proteins ICP4 and ICP0, E proteins ICP6 and OBP, and $\mathrm{L}$ protein ICP9 $(\mathrm{gB})$.

inine-labeled OBP was detected in cells superinfected with hr94 (lanes 4 and 5) than in cells superinfected with UVinactivated KOS (lane 2) or $n 12$ (lane 3), the levels of $\left[{ }^{32} \mathrm{P}\right]$ orthophosphate-labeled OBP were highest in cells superinfected with hr94 (lanes 9 and 10).

To confirm the status of viral DNA replication in superinfected cells, slot blot analysis of total DNA from infected cells was performed (Fig. 5C). Whereas efficient viral DNA replication was detected in cells infected with KOS or in AdOBPinfected cells superinfected with $h r 94$ (in the latter case, viral DNA replication was induced via complementation), the addition of PAA inhibited viral DNA replication to the level detected in mock-infected cells. As expected, the level of HSV DNA replication in cells infected with $h r 94$, AdOBP, or AdOBP plus $n 12$ was similar to that observed in mock-infected cells.

To confirm the status of viral protein synthesis in superinfected cells, SDS-polyacrylamide gel electrophoresis (PAGE) analysis of $\left[{ }^{35} \mathrm{~S}\right]$ methionine-labeled proteins was performed (Fig. 5D). AdOBP-infected cells were either mock infected or infected with $n 12$ or $h r 94$ in the presence or absence of PAA and then labeled with $\left[{ }^{35} \mathrm{~S}\right]$ methionine from 3 to $10 \mathrm{~h}$ after superinfection. KOS-infected cells were also labeled as a control for viral protein synthesis. In KOS-infected cells, synthesis of ICP4 (immediate-early [IE] protein), ICP6 (E protein), ICP0 (IE protein), and ICP9 (gB; L protein) was observed; synthesis of OBP was below detectable levels in KOS-infected cells (lane 1). As expected, OBP was the only protein synthesized in cells infected with AdOBP alone. AdOBP-infected cells superinfected with $n 12$ expressed both ICP0 and the ICP0-inducible ICP6-encoding gene (albeit at reduced levels compared to KOS-infected cells) but, as anticipated, not IE protein ICP4 or L protein $\mathrm{gB}$. These results are consistent with previous reports which demonstrate that synthesis of $\mathrm{E}$ and $\mathrm{L}$ proteins is inhibited in the absence of ICP4 (11). In AdOBPinfected cells superinfected with $h r 94$ in the absence of PAA, the profile of viral protein synthesis (induced via complementation) was similar to that in KOS-infected cells, with the exception that synthesis of OBP was detectable in the latter (lane 5) but not in the former (lane 1). Addition of PAA to AdOBP-infected cells superinfected with $h r 94$ altered the pat-

tern of viral protein synthesis slightly, as the intensity of the ICP6 band was slightly greater than that in KOS-infected cells, presumably due to an accumulation of E proteins upon inhibition of HSV DNA replication (lane 4). Detection of $\mathrm{gB}$ in these cells is consistent with its classification as a $\gamma_{1} \mathrm{~L}$ protein.

Based on the low level of phosphorylated OBP in AdOBPinfected cells superinfected with $n 12$, in which E gene expression is inhibited (Fig. 5B, lane 8) relative to the higher level observed in AdOBP-infected cells superinfected with $h r 94$ in the presence of PAA, in which HSV DNA replication is inhibited (Fig. 5B, lane 9), we conclude that HSV-induced phosphorylation of OBP is likely (i) dependent on expression of HSV E proteins and (ii) independent of HSV DNA replication. Notably, however, we cannot eliminate the possibility that ICP4 is directly responsible for the increase in OBP phosphorylation, since ICP4 is not expressed in AdOBP-infected cells superinfected with $n 12$.

HSV-induced phosphorylation of OBP does not affect its ability to bind to OriS site I. Given that phosphorylation has been shown to regulate the origin binding activity of other viral replication initiator proteins, we sought to determine whether the phosphorylation state of OBP affects its ability to form protein-DNA complexes at its highest-affinity binding site, site I. AdOBP-infected Vero cells, which exhibit minimal phosphorylation of OBP, and AdOBP-infected cells superinfected with $h r 94$, which exhibit increased phosphorylation of OBP, were harvested $10 \mathrm{~h}$ after superinfection with $\mathrm{hr} 94$, and nuclear extracts were prepared. Vero cells infected with KOS or $h r 94$ were included as positive and negative controls, respectively, for the expression of OBP. The ability of OBP to bind to a double-stranded DNA probe containing OriS site I was then analyzed in gel mobility shift assays (Fig. 6). Although site I (10 bp) is the same in both OriS and OriL, this probe (26 bp) extends beyond site I and includes two base pairs which are specific to OriS. In addition to two cellular protein complexes that bind to site I DNA (Fig. 6, arrowheads), proteins in nuclear extracts of KOS-infected Vero cells (lane 1) form three 


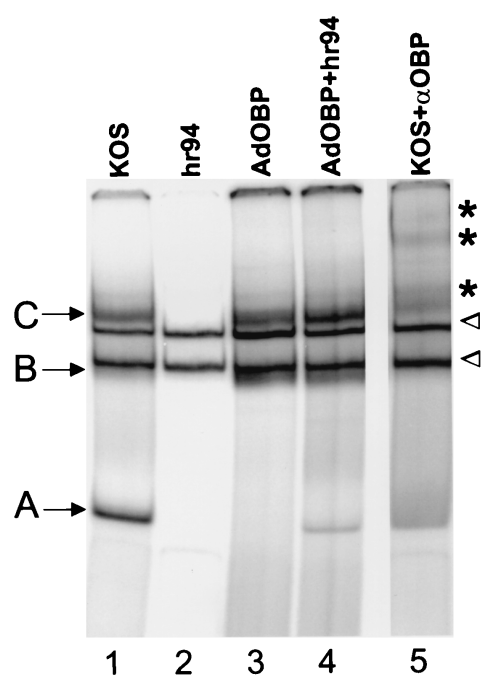

FIG. 6. HSV-induced phosphorylation does not affect the origin binding activity of OBP. Vero cells infected at $50 \mathrm{PFU} /$ cell with KOS, $h r 94$, AdOBP, and AdOBP plus $h r 94$ were harvested at $10 \mathrm{hpi}$, and nuclear extracts were prepared and analyzed for origin binding activity in gel mobility shift assays. Five micrograms of nuclear protein was incubated with the OriS site I probe. Protein-DNA complexes were resolved in a nondenaturing $6 \%$ polyacrylamide gel and visualized using a PhosphorImager. Addition of antibody to OBP (R250) shifted the mobility of OBP-containing complexes (complexes B and C) and the OBPC-containing complex (complex A). Cellular complexes are indicated by arrowheads, and supershifted bands are indicated by asterisks (lane 5).

site I binding complexes, designated complexes A, B, and C, which are not present in $h r 94$-infected cells (lane 2). Addition of an antibody (R250) which recognizes the $\mathrm{C}$ terminus of OBP, and thus also recognizes OBPC, shifted the mobility of complexes A, B, and C (lane 5; shifted bands are indicated by asterisks). Previous work in our laboratory has shown that these complexes contain the following proteins: complex A contains OBPC, and complexes $\mathrm{B}$ and $\mathrm{C}$ contain OBP and likely other cellular proteins $(9,4)$. Complexes B and $C$ (which contain OBP) were detected in nuclear extracts of both AdOBP-infected cells (lane 3) and AdOBP-infected cells superinfected with $h r 94$ (lane 4), suggesting that HSV-induced phosphorylation of OBP (1) is not required for, and (2) does not affect, the origin binding activity of OBP. No detectable binding of the OBPC-containing complex (complex A) was detected using nuclear extracts of AdOBP-infected cells (lane 3); however, a low level of complex A was detected using nuclear extracts of AdOBP-infected cells superinfected with hr94 (lane 4). This finding may reflect transcriptional activation of the OBPC promoter (present within the OBP ORF of AdOBP) by HSV factors provided in trans by superinfection of AdOBP-infected cells with $h r 94$ but not present in cells infected with AdOBP alone.

Phosphatase treatment affects the mobility of an OBP-containing complex bound to site I. Using a second method to evaluate the role of phosphorylation in the site I binding activity of OBP, we used phosphatases to dephosphorylate proteins present in nuclear extracts from KOS-infected cells. Nuclear extracts prepared from KOS-infected Vero cells were treated with increasing amounts of $\lambda$ protein phosphatase, and
OBP binding to the site I probe was evaluated in gel shift assays (Fig. 7A). In untreated nuclear extracts of KOS-infected cells, we observed binding of complexes $\mathrm{A}$ and $\mathrm{C}$ and, to a much lesser extent, complex B (lane 4). It is worth noting that the binding of cellular protein complexes is much less prominent here than in Fig. 6 (arrowheads). The intensity of these complexes varies, depending on the status of the Vero cell monolayer used for extract preparation, as well as the nuclear extract preparation itself. Binding of complexes A, B, and C was not detected in samples which did not contain nuclear extract (probe, lane 1) or in samples which contained mockinfected nuclear extracts (mock, lane 2). As shown previously, complexes A, B, and $\mathrm{C}$ were shifted upon addition of an antibody to OBP (R250; lane 3; supershifted complexes are indicated by asterisks). Due to the low intensity of complex B in this gel, antibody supershift of this complex was not detectable. Addition of increasing amounts of $\lambda$ protein phosphatase resulted in a slight upward shift in the electrophoretic mobility of complex $\mathrm{C}$, as well as a slight increase in the intensity of complex A (lanes 4 to 8). Both the increase in electrophoretic mobility of complex $\mathrm{C}$ and the increase in intensity of complex A occurred in a dose-dependent manner, as the most pronounced effects were observed upon addition of the greatest amount of phosphatase ( $4 \mu \mathrm{l}$; lane 8$)$. As a control for the

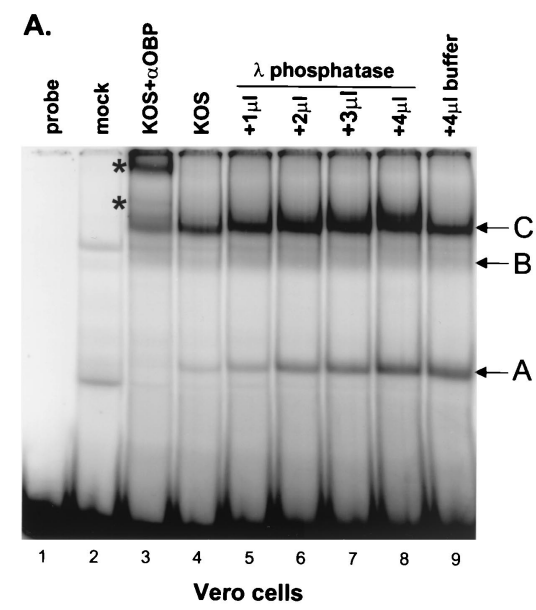

B.

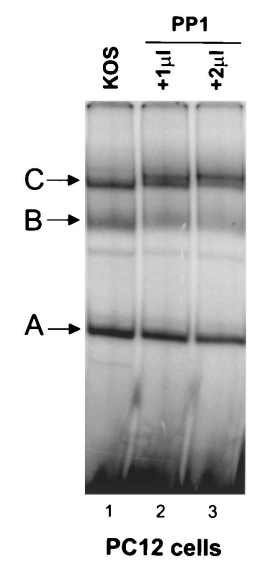

FIG. 7. Phosphatase treatment alters the electrophoretic mobility of OBP-containing complex C bound to site I. (A) Vero cells were infected at $10 \mathrm{PFU} / \mathrm{cell}$ with KOS and harvested at $16 \mathrm{hpi}$, and nuclear extracts were prepared. Five micrograms of nuclear protein was either left untreated (lane 4) or treated with $1,2,3$, or $4 \mu$ l of $\lambda$ protein phosphatase (lanes 5 to 8 ) or with $4 \mu$ l of phosphatase storage buffer as described in the text (lane 9). Phosphatase-treated extracts were then incubated with the OriS site I probe as described in the text. Incubation of the OriS site I probe without extract (lane 1), with mock-infected extract (lane 2), or with KOS-infected extract in the presence of antibody to OBP (R250; lane 3) was also performed. Protein-DNA complexes were resolved in a nondenaturing $6 \%$ polyacrylamide gel and visualized using a PhosphorImager. Addition of antibody to OBP (R250) shifted the mobility of complexes A and C as indicated by the asterisks (lane 3). The intensity of complex B is weaker here than it is in Fig. 5. (B) NGF-differentiated PC12 cells were infected at $10 \mathrm{PFU} / \mathrm{cell}$ with KOS and harvested at $10 \mathrm{hpi}$, and nuclear extracts were prepared. Five micrograms of nuclear protein was untreated (lane 1) or treated with 1 (lane 2) or 2 (lane 3) $\mu$ l of PP1. Binding to the OriS site I probe was evaluated by gel shift analysis as described for panel A. 
effects of glycerol and other components in the buffer used to store the enzyme, $4 \mu \mathrm{l}$ of phosphatase storage buffer (containing no phosphatase) was added to nuclear extracts (lane 9). The mobility of complex $\mathrm{C}$ was not affected by treatment with $4 \mu \mathrm{l}$ of storage buffer, suggesting that alteration of complex $\mathrm{C}$ is a result of phosphatase activity. In contrast, addition of $4 \mu \mathrm{l}$ of storage buffer increased the intensity of complex A to the same degree as treatment with $4 \mu \mathrm{l}$ of $\lambda$ phosphatase, suggesting that the effect on complex $\mathrm{A}$ is a result of buffer components and not of $\lambda$ phosphatase. The slight decrease in the mobility of complex A was not observed in similar experiments and appears to be the result of irregular gel electrophoresis in the last lane of the gel (Fig. 7A, lane 9).

Similar results were obtained in gel shift assays using extracts from HSV-infected, NGF-differentiated PC12 cells treated with another phosphatase, PP1 (Fig. 7B). In untreated extracts from infected cells, we observed binding of three complexes, A, $\mathrm{B}$, and $\mathrm{C}$ (lane 1). Treatment with $1 \mu \mathrm{l}$ (lane 2) or $2 \mu \mathrm{l}$ (lane 3 ) of PP1 shifted the mobility of complex C, or at least a subset of complex $\mathrm{C}$, resulting in the appearance of a band with mobility slightly lower than that of complex C. This effect was not observed upon addition of the same amounts of PP1 storage buffer (data not shown). These results are consistent with those observed upon $\lambda$ phosphatase treatment of nuclear extracts of HSV-infected Vero cells (Fig. 7A). Addition of PP1 decreased the intensity of complex B slightly; however, the same effect was observed upon addition of PP1 storage buffer (data not shown), suggesting that PP1 activity is not responsible for the effect on complex B. Addition of PP1 had no effect on complex A formation.

Whether the effects of $\lambda$ and PP1 phosphatase treatment on complex $\mathrm{C}$ are due to dephosphorylation of OBP or of another protein within this complex is not clear; however, these observations suggest that although phosphatase treatment may alter the mobility of an OBP-containing complex bound to site I (complex C), the origin binding capacity of OBP is not detectably affected.

\section{DISCUSSION}

Prior to this study, the low level of OBP synthesized in HSV-infected cells had prevented the identification of posttranslational modifications that might regulate OBP function. In this study, the use of metabolic labeling and immunoprecipitation enabled us to demonstrate that OBP, like other replication initiator proteins, is phosphorylated during viral infection (Fig. 2).

An HSV E gene function(s) is required for OBP phosphorylation. Consistent with an increase in OBP phosphorylation, kinetic studies of OBP synthesis revealed that multiple, slowermigrating forms of $\mathrm{OBP}$ are produced as a function of time postinfection (Fig. 3A). To determine whether OBP phosphorylation is dependent on factors expressed during HSV infection, we infected cells with a recombinant adenovirus expressing OBP and found that in the absence of other HSV factors, OBP is phosphorylated minimally, if at all. In contrast, in AdOBP-infected cells superinfected with $h r 94$, which provides all other HSV factors in trans, the level of OBP phosphorylation, but not OBP synthesis, was increased threefold (Fig. 4C). Superinfection of AdOBP-infected cells with HSV mutants inhibited at sequential stages of HSV replication indicated that the increase in OBP phosphorylation is dependent on HSV E proteins or cellular proteins induced by $\mathrm{E}$ proteins, as increased phosphorylation of OBP was not observed in the presence of an ICP4 mutant (defective in E protein synthesis) (Fig. 5). As noted above, that ICP4 itself may be responsible for the phosphorylation of OBP remains a theoretical possibility. Based on these observations, we conclude that phosphorylation of OBP depends, either directly or indirectly, on an HSV E protein function(s). In contrast, inhibition of HSV DNA synthesis by addition of PAA did not affect the ability of $h r 94$ to enhance the level of OBP phosphorylation, suggesting that HSV-specific phosphorylation of OBP is independent of HSV DNA replication. Given that PAA inhibits viral DNA replication at the level of elongation, it is possible that phosphorylation of OBP requires the formation of the HSV DNA replication complex and/or initiation of origin-dependent DNA synthesis.

Do cellular or viral kinases phosphorylate OBP? A number of cellular kinases have been shown to phosphorylate replication initiator proteins in other viral systems. These include the cyclin-dependent kinase 1 (SV40 TAg and BPV E1) $(32,23)$, protein kinase C (BPV E1 and MVM NS1) $(51,12)$, and casein kinase II (BPV E1) (32), among others. Although the kinase(s) that phosphorylates OBP has not yet been identified, consensus sites for many cellular kinases exist based on amino acid sequence analysis. The low level of $\left[{ }^{32} \mathrm{P}\right]$ orthophosphate-labeled OBP detected in HSV-infected cells suggests that unlike SV40 TAg, which is phosphorylated at many sites by a number of cellular kinases, phosphorylation of OBP is likely limited to a subset of OBP molecules and/or occurs at a limited number of sites within OBP. Whereas phosphorylation of OBP was undetectable in $293 \mathrm{~T}$ cells transfected with an OBP-expressing plasmid (Fig. 4A) and in Sf9 cells infected with an OBP-expressing baculovirus (Fig. 4B), a very low level of OBP phosphorylation was detected in Vero cells infected with an OBP-expressing adenovirus (Fig. 4C). The reason for these differences is not clear; however, it is possible that vector-encoded viral gene products expressed from AdOBP, but not from pCMVUL9 or AcNPVOBP, may induce low levels of OBP phosphorylation. Specifically, the adenovirus E4 gene present in these vectors has been shown to induce changes in cell cycle regulated proteins, and thus it is a theoretical possibility that these vectors induce the activity of kinases which phosphorylate OBP (52). With regard to cell type, it should be noted that we were unable to detect phosphorylation of OBP in Vero cells transfected with an OBP expression plasmid (pCMVUL9; data not shown), indicating that cellular kinases active following transfection of two different cell types (293T and Vero cells) do not phosphorylate OBP to detectable levels. With regard to levels of OBP protein synthesized, despite very high levels of OBP synthesis, we were unable to detect phosphorylation of OBP in Sf9 cells infected with AcNPVUL9 at a high MOI, suggesting that in these cells, low levels of OBP are not responsible for our inability to detect OBP phosphorylation.

That HSV E gene expression increases the level of OBP phosphorylation suggests that OBP is phosphorylated, at least in part, by an HSV-encoded E kinase or by a cellular kinase induced by an HSV E protein. Of the recognized HSV-encoded kinases (US3 and UL13), US3 is expressed with E ki- 
netics; however, OBP does not contain the suggested consensus phosphorylation site for US3, and thus, it is unlikely that US3 phosphorylates OBP during HSV infection $(15,22,41)$. UL13, a virion protein expressed with L kinetics (38), is not likely to be involved in OBP phosphorylation since (i) increased phosphorylation of OBP was not observed in AdOBPinfected cells superinfected with UV-inactivated KOS (in which virion proteins are present) and (ii) increased phosphorylation of OBP was observed in AdOBP-infected cells superinfected with $h r 94$ and treated with PAA (in which L protein synthesis is inhibited). With regard to virus-induced cellular kinases, published reports indicate that HSV infection increases the activity of cdk1, as well as cJun N-terminal kinase $(2,30)$; however, since this list is likely incomplete, identification of the specific kinases which phosphorylate OBP requires a more extensive, directed effort.

Relationship between phosphorylation state and function of baculovirus-expressed OBP. As demonstrated nearly a decade ago, the seven essential HSV DNA replication proteins, when expressed by baculovirus infection of insect cells, can support amplification of an HSV origin-containing plasmid, suggesting that any host cell function essential for HSV DNA replication in mammalian cells must also be present in baculovirus-infected insect cells (45). Notably, however, we were unable to detect phosphorylation of OBP in baculovirus-infected insect cells, despite high levels of OBP synthesis. One possible explanation is that phosphorylation of OBP is not required for viral DNA synthesis. On the other hand, we cannot rule out the possibility that phosphorylation of OBP requires the expression of other essential HSV DNA replication proteins or the presence of a functional HSV origin. Thus, it is possible that in the presence of other essential HSV replication factors, baculovirus-expressed OBP is phosphorylated in insect cells. Our observation that phosphorylation of OBP is, in part, dependent on the synthesis of HSV E proteins supports this possibility (Fig. 5), and efforts are ongoing to test this possibility definitively.

Work in many laboratories has demonstrated that OBP expressed alone in Sf9 cells exhibits (i) origin binding activity (36), (ii) the ability to form dimers both in solution and when bound to HSV origins (14), (iii) DNA-stimulated ATPase and ATP-dependent helicase activities (14), (iv) the ability to loop and distort the HSV replication origin (21), and (v) the ability to interact with UL8, UL42, ICP8, and the cellular DNA polymerase $\alpha(5,22,29,33)$. Again, given that we were unable to detect phosphorylation of OBP in AcNPVUL9-infected Sf9 cells, it is possible that phosphorylation is not required for the aforementioned functional activities of OBP. It is also possible, however, that phosphorylation indeed influences OBP function during lytic infection where, in contrast to in vitro experiments with purified proteins, the activity of OBP is likely influenced by the abundance and/or subcellular localization of replication factors, as well as other intracellular conditions.

Does phosphorylation play a role in the replication initiator function of OBP? Phosphorylation is commonly used in eukaryotic and animal viral replication systems to control the initiation of DNA replication, often by direct phosphorylation of the replication initiator protein. Particularly in the case of HSV, where viral DNA synthesis appears to be a critical regulatory event at the branch point between the lytic and latent pathways, the initiation of DNA replication is likely subject to strict regulation (35), and thus, phosphorylation of OBP may serve an important regulatory function. Moreover, the fact that phosphorylation of OBP is not constitutive but rather appears to be dependent, at least in part, on HSV infection may reflect the importance of this modification for OBP function. Therefore, we continue to hypothesize that phosphorylation may regulate an essential DNA replication function(s) of OBP. The contrast between other viral replication initiator proteins and HSV OBP (i.e., that OBP is synthesized and phosphorylated at low levels and phosphorylation is in part dependent on HSVencoded E proteins versus the fact that the SV40 and polyomavirus TAgs, BPV E1, and MVM NS1 are synthesized in greater amounts and are highly phosphorylated by cellular kinases independently of viral infection) is of considerable interest. The effects of the observed differences in the level of initiator protein synthesis and phosphorylation on the pathogenesis of these viruses remain to be determined.

Our results suggest that phosphorylation of OBP does not affect its origin binding activity (Fig. 6 and 7). These observations are consistent with previous findings which demonstrate that both OBPC and the DNA binding domain of OBP, when expressed in bacteria in an unphosphorylated state, exhibit sequence-specific binding to OriS site I (unpublished observation; 27). Likewise, phosphorylation is not likely to be required for nuclear localization of OBP, as OBP has been shown to localize to the nucleus in transfected Vero cells (26), in which we were unable to detect OBP phosphorylation. We also observed efficient nuclear localization of OBP in transfected Vero cells, as well as in AdOBP-infected Vero cells (data not shown), in which we detected very low levels of OBP phosphorylation. Elucidation of the precise role of OBP phosphorylation in its replication initiator function requires the identification of phosphorylation sites within the protein such that phosphorylation-defective mutants can be generated and subsequently analyzed in specific functional assays.

\section{ACKNOWLEDGMENTS}

These studies were funded by NIAID research grant RO1-A128537. J.A.I. was also supported by training grant NIHT32-AI-07325.

We gratefully acknowledge Mark Challberg for providing antisera to OBP, Ellen Fanning for providing SV40 TAg-expressing baculovirus, Debbie Parris for providing OBP-expressing baculovirus (with permission from Bob Lehman) and antisera to OBP (with permission from Dan Tenney), Sandy Weller for providing $h r 94$ and 2B.11 cells, and Bill Halford for his collaborative efforts in constructing recombinant adenoviruses. We also thank the members of the Schaffer laboratory for helpful discussions and ideas.

\section{REFERENCES}

1. Ackermann, M., D. K. Braun, L. Pereira, and B. Roizman. 1984. Characterization of herpes simplex virus 1 alpha proteins 0 , 4, and 27 with monoclonal antibodies. J. Virol. 52:108-118.

2. Advani, S. J., R. Brandimarti, R. R. Weichselbaum, and B. Roizman. 2000. The disappearance of cyclins $\mathrm{A}$ and $\mathrm{B}$ and the increase in activity of the $\mathrm{G}_{2} / \mathrm{M}$-phase cellular kinase cdc2 in herpes simplex virus 1-infected cells require expression of the $\alpha 22 / \mathrm{U}_{\mathrm{S}} 1.5$ and $\mathrm{U}_{\mathrm{L}} 13$ viral genes. J. Virol. 74:8-15.

3. Baradaran, K., C. E. Dabrowski, and P. A. Schaffer. 1994. Transcriptional analysis of the region of the herpes simplex virus type 1 genome containing the UL8, UL9, and UL10 genes and identification of a novel delayed-early gene product, OBPC. J. Virol. 68:4251-4261.

4. Baradaran, K., M. A. Hardwicke, C. E. Dabrowski, and P. A. Schaffer. 1996. Properties of the novel herpes simplex virus type 1 origin binding protein, OBPC. J. Virol. 70:5673-5679.

5. Boehmer, P. E., M. C. Craigie, N. D. Stow, and I. R. Lehman. 1994. Association of origin binding protein and single strand DNA-binding protein, 
ICP8, during herpes simplex virus type 1 DNA replication in vivo. J. Biol. Chem. 269:29329-29334.

6. Boehmer, P. E., M. S. Dodson, and I. R. Lehman. 1993. The herpes simplex virus type-1 origin binding protein. DNA helicase activity. J. Biol. Chem. 268: $1220-1225$

7. Boehmer, P. E., and I. R. Lehman. 1997. Herpes simplex virus DNA replication. Annu. Rev. Biochem. 66:347-384.

8. Cai, W., and P. A. Schaffer. 1988. Herpes simplex virus type 1 ICP0 plays a critical role in the de novo synthesis of infectious virus following transfection of viral DNA. J. Virol. 63:4579-4589.

9. Dabrowski, C. E., and P. A. Schaffer. 1991. Herpes simplex virus type 1 origin-specific binding protein: oriS-binding properties and effects of cellular proteins. J. Virol. 65:3140-3150.

10. DeLuca, N. A., and P. A. Schaffer. 1985. Activation of immediate-early, early, and late promoters by temperature-sensitive and wild-type forms of herpes simplex virus type 1 protein ICP4. Mol. Cell. Biol. 5:1997-2008.

11. DeLuca, N. A., and P. A. Schaffer. 1988. Physical and functional domains of the herpes simplex virus transcriptional regulatory protein ICP4. J. Virol. 62:732-743.

12. Dettweiler, S., J. Rommelaere, and J. P. F. Nüesch. 1999. DNA unwinding functions of minute virus of mice NS1 protein are modulated specifically by the lambda isoform of protein kinase C. J. Virol. 73:7410-7420.

13. Dodson, M. S., and I. R. Lehman. 1993. The herpes simplex virus type 1 origin binding protein. DNA-dependent nucleoside triphosphatase activity. J. Biol. Chem. 268:1213-1219.

14. Fierer, D. S., and M. D. Challberg. 1992. Purification and characterization of UL9, the herpes simplex virus type 1 origin-binding protein. J. Virol. 66: 3986-3995.

15. Frame, M. C., F. C. Purves, D. J. McGeoch, H. S. Marsden, and D. P. Leader. 1987. Identification of the herpes simplex virus protein kinase as the product of the viral gene US3. J. Gen. Virol. 68:2699-2704.

16. Hardwicke, M. A., and P. A. Schaffer. 1997. Differential effects of nerve growth factor and dexamethasone on herpes simplex virus type 1 oriL- and oriS-dependent DNA replication in PC12 cells. J. Virol. 71:3580-3587.

17. Hazuda, D. J., H. C. Perry, and W. L. McClements. 1992. Cooperative interactions between replication origin-bound molecules of herpes simplex virus origin-binding protein are mediated via the amino terminus of the protein. J. Biol. Chem. 267:14309-14315.

18. Heilbronn, R., and H. zur Hausen. 1989. A subset of herpes simplex virus replication genes induces DNA amplification within the host cell genome. J. Virol. 63:3683-3692.

19. Hoss, A., I. Moarefi, K. H. Scheidtmann, L. J. Cisek, J. L. Corden, I. Dornreiter, A. K. Arthur, and E. Fanning. 1990. Altered phosphorylation pattern of simian virus $40 \mathrm{~T}$ antigen expressed in insect cells by using a baculovirus vector. J. Virol. 64:4799-4807.

20. Kaerner, H. C., I. B. Maichle, A. Ott, and C. H. Schroder. 1979. Origins of two different classes of defective HSV-1 Angelotti DNA. Nucleic Acids Res. 6:1467-1478

21. Koff, A., J. F. Schwedes, and P. Tegtmeyer. 1991. Herpes simplex virus origin-binding protein (UL9) loops and distorts the viral replication origin. J. Virol. 65:3284-3292.

22. Leader, D. P., A. D. Deana, F. Marchiori, F. C. Purves, and L. A. Pinna. 1991. Further definition of the substrate specificity of the alpha-herpesvirus protein kinase and comparison with protein kinases $\mathrm{A}$ and $\mathrm{C}$. Biochim. Biophys. Acta. 1091:426-431.

23. Lee, A. S.-K., Q. Dong, T. S.-F. Wang, and I. R. Lehman. 1995. Interaction of herpes simplex virus 1 origin-binding protein with DNA polymerase alpha. Proc. Natl. Acad. Sci. USA 92:7882-7886.

24. Lentz, M. R., D. Pak, I. Mohr, and M. R. Botchan. 1993. The E1 replication protein of bovine papillomavirus type 1 contains an extended nuclear localization signal that includes a p34 ${ }^{\mathrm{cdc} 2}$ phosphorylation site. J. Virol. 67:14141423.

25. Makhov, A. M., P. E. Boehmer, I. R. Lehman, and J. D. Griffith. 1996. The herpes simplex virus type 1 origin-binding protein carries out origin specific DNA unwinding and forms stem-loop structures. EMBO J. 15:1742-1750.

26. Malik, A., L. Shao, J. D. Shanley, and S. K. Weller. 1996. Intracellular localization of the herpes simplex virus type-1 origin binding protein, UL9. Virology 224:380-389.

27. Malik, D. K., R. Martinez, L. Muncy, E. P. Carmichael, and S. K. Weller. 1992. Genetic analysis of the herpes simplex virus type 1 UL9 gene: isolation of a lacZ insertion mutant and expression in eukaryotic cells. Virology 190:702-715.

28. Martinez, R., and C. A. Edwards. 1993. Expression, purification, and functional characterization of the DNA-binding domain of the herpes simplex virus type 1 UL9 protein. Protein Expr. Purif. 4:32-37.

29. Martinez, R., L. Shao, and S. K. Weller. 1992. The conserved helicase motifs of the herpes simplex virus type 1 origin-binding protein UL9 are important for function. J. Virol. 66:6735-6746.

30. McLean, G. W., A. P. Abbotts, M. E. Parry, H. S. Marsden, and N. D. Stow.
1994. The herpes simplex virus type 1 origin-binding protein interacts specifically with the viral UL8 protein. J. Gen. Virol. 75:2699-2706.

31. McLean, T. I., and S. L. Bachenheimer. 1999. Activation of cJUN N-terminal kinase by herpes simplex virus type 1 enhances viral replication. J. Virol. 73:8415-8426.

32. McShan, G. D., and V. G. Wilson. 1997. Casein kinase II phosphorylates bovine papillomavirus type $1 \mathrm{E} 1$ in vitro at a conserved motif. J. Gen. Virol. 78:171-177.

33. McVey, D., L. Brizuela, I. Mohr, D. R. Marshak, Y. Iuzman, and D. Beach. 1989. Phosphorylation of large tumour antigen by cdc2 stimulates SV40 DNA replication. Nature 341:503-507.

34. Monahan, S. J., L. A. Grinstead, W. Olivieri, and D. S. Parris. 1998. Interaction between the herpes simplex virus type 1 origin-binding and DNA polymerase accessory proteins. Virology 241:122-130.

35. Nichol, P. F., J. Y. Chang, E. M. J. Johnson, and P. D. Olivo. 1996. Herpes simplex virus gene expression in neurons: viral DNA synthesis is a critical regulatory event in the branch point between the lytic and latent pathways. J. Virol. 70:5476-5486.

36. Olivo, P. D., N. J. Nelson, and M. D. Challberg. 1988. Herpes simplex virus DNA replication: the UL9 gene encodes an origin-binding protein. Proc. Natl. Acad. Sci. USA 85:5414-5418.

37. Olivo, P. D., N. J. Nelson, and M. D. Challberg. 1989. Herpes simplex virus type 1 gene products required for DNA replication: identification and overexpression. J. Virol. 63:196-204.

38. Overton, H. A., D. J. McMillan, L. S. Klavinskis, L. Hope, A. J. Ritchie, and P. Wong-kai-in. 1992. Herpes simplex virus type 1 gene UL13 encodes a phosphoprotein that is a component of the virion. Virology 190:184-192.

39. Perry, H. C., D. J. Hazuda, and W. L. McClements. 1993. The DNA binding domain of herpes simplex virus type 1 origin binding protein is a transdominant inhibitor of virus replication. Virology 193:73-79.

40. Prives, C. 1990 . The replication functions of SV40 T antigen are regulated by phosphorylation. Cell 61:735-738.

41. Purves, F. C., A. D. Deana, F. Marchiori, D. P. Leader, and L. A. Pinna. 1986. The substrate specificity of the protein kinase induced in cells infected with herpesviruses: studies with synthetic substrates indicate structural requirements distinct from other protein kinases. Biochim. Biophys. Acta 889:208-215.

42. Rabkin, S. D., and B. Hanlon. 1990. Herpes simplex virus DNA synthesis at a preformed replication fork in vitro. J. Virol. 64:4957-4967.

43. Schang, L. M., J. Phillips, and P. A. Schaffer. 1998. Requirement of cellular cyclin-dependent kinases in herpes simplex virus replication and transcription. J. Virol. 72:5626-5637.

44. Skaliter, R., and I. R. Lehman. 1994. Rolling circle DNA replication in vitro by a complex of herpes simplex virus type 1-encoded enzymes. Proc. Natl. Acad. Sci. USA 91:10665-10669.

45. Stow, N. D. 1992 . Herpes simplex virus type 1 origin-dependent DNA replication in insect cells using recombinant baculoviruses. J. Gen. Virol. 73: 313-321.

46. Stow, N. D. 1982. Localization of an origin of DNA replication within the TRs/IRs repeated region of the herpes simplex virus type 1 genome. EMBO J. 1:863-867.

47. Stow, N. D., O. Hammarsten, M. I. Arbuckle, and P. Elias. 1993. Inhibition of herpes simplex virus type 1 DNA replication by mutant forms of the origin-binding protein. Virology 196:413-418.

48. Virshup, D. M., A. A. R. Russo, and T. J. Kelly. 1992. Mechanism of activation of simian virus 40 DNA replication by protein phosphatase $2 \mathrm{~A}$. Mol. Cell. Biol. 12:4883-4895.

49. Wang, E. H., S. Bhattacharyya, and C. Prives. 1993. The replication functions of polyomavirus large tumor antigen are regulated by phosphorylation. J. Virol. 67:6788-6796.

50. Weisshart, K., and E. Fanning. 1996. Roles of phosphorylation in DNA replication, p. 295-330. In M. L. DePamphilis (ed.), DNA replication in eukaryotic cells. Cold Spring Harbor Laboratory Press, Cold Spring Harbor, N.Y.

51. Weller, S. K., S. Spadaro, J. E. Schaffer, A. W. Murray, A. M. Maxam, and P. A. Schaffer. 1985. Cloning, sequencing, and functional analysis of ori $_{\mathrm{L}}$, a herpes simplex virus type 1 origin of DNA synthesis. Mol. Cell. Biol. 5:930942.

52. Wertso, R. P., E. R. Rosenthal, P. K. Seth, N. T. Eissa, and R. E. Donahue. 1998. Recombinant, replication-defective adenovirus gene transfer vectors induce cell cycle dysregulation and inappropriate expression of cyclin proteins. J. Virol. 72:9491-9502.

53. Wu, C. A., N. J. Nelson, D. J. McGeoch, and M. D. Challberg. 1988. Identification of herpes simplex virus type 1 genes required for origin-dependent DNA synthesis. J. Virol. 62:435-443.

54. Zanardi, T. A., C. M. Stanley, B. M. Saville, S. M. Spacek, and M. R. Lentz. 1997. Modulation of bovine papillomavirus DNA replication by phosphorylation of the viral E1 protein. Virology 228:1-10. 